\title{
Physical mapping resources for large plant genomes: radiation hybrids for wheat D-genome progenitor Aegilops tauschii
}

Ajay Kumar ${ }^{1}$, Kristin Simons ${ }^{1}$, Muhammad J lqbal', Monika Michalak de Jiménez', Filippo M Bassi', Farhad Ghavami ${ }^{1}$, Omar Al-Azzam ${ }^{2,6}$, Thomas Drader ${ }^{3}$, Yi Wang $^{3}$, Ming-Cheng Luo ${ }^{4}$, Yong Q Gu ${ }^{3}$, Anne Denton ${ }^{2}$,

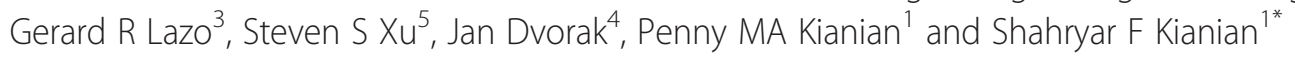

\begin{abstract}
Background: Development of a high quality reference sequence is a daunting task in crops like wheat with large $(\sim 17 \mathrm{~Gb})$, highly repetitive (>80\%) and polyploid genome. To achieve complete sequence assembly of such genomes, development of a high quality physical map is a necessary first step. However, due to the lack of recombination in certain regions of the chromosomes, genetic mapping, which uses recombination frequency to map marker loci, alone is not sufficient to develop high quality marker scaffolds for a sequence ready physical map. Radiation hybrid $(\mathrm{RH})$ mapping, which uses radiation induced chromosomal breaks, has proven to be a successful approach for developing marker scaffolds for sequence assembly in animal systems. Here, the development and characterization of a RH panel for the mapping of D-genome of wheat progenitor Aegilops tauschii is reported.

Results: Radiation dosages of 350 and 450 Gy were optimized for seed irradiation of a synthetic hexaploid (AABBDD) wheat with the D-genome of Ae. tauschii accession AL8/78. The surviving plants after irradiation were crossed to durum wheat (AABB), to produce pentaploid $\mathrm{RH}_{1} \mathrm{~S}(\mathrm{AABBD})$, which allows the simultaneous mapping of the whole D-genome. A panel of 1,510 $\mathrm{RH}_{1}$ plants was obtained, of which 592 plants were generated from the mature $\mathrm{RH}_{1}$ seeds, and 918 plants were rescued through embryo culture due to poor germination $(<3 \%)$ of mature $\mathrm{RH}_{1}$ seeds. This panel showed a homogenous marker loss (2.1\%) after screening with SSR markers uniformly covering all the D-genome chromosomes. Different marker systems mostly detected different lines with deletions. Using markers covering known distances, the mapping resolution of this $\mathrm{RH}$ panel was estimated to be $<140 \mathrm{~kb}$. Analysis of only $16 \mathrm{RH}$ lines carrying deletions on chromosome 2D resulted in a physical map with $c M / c R$ ratio of 1:5.2 and 15 distinct bins. Additionally, with this small set of lines, almost all the tested ESTs could be mapped. A set of 399 most informative RH lines with an average deletion frequency of $\sim 10 \%$ were identified for developing high density marker scaffolds of the D-genome.
\end{abstract}

Conclusions: The RH panel reported here is the first developed for any wild ancestor of a major cultivated plant species. The results provided insight into various aspects of $\mathrm{RH}$ mapping in plants, including the genetically effective cell number for wheat (for the first time) and the potential implementation of this technique in other plant species. This $\mathrm{RH}$ panel will be an invaluable resource for mapping gene based markers, developing a complete marker scaffold for the whole genome sequence assembly, fine mapping of markers and functional characterization of genes and gene networks present on the D-genome.

Keywords: Aegilops tauschii, Genetically effective cell number, Physical mapping, Radiation hybrid mapping, Repeat DNA junction marker, Wheat

\footnotetext{
* Correspondence: s.kianian@ndsu.edu

'Department of Plant Sciences, North Dakota State University, Fargo, ND 58108, USA

Full list of author information is available at the end of the article
}

\section{Biomed Central}

(c) 2012 Kumar et al.; licensee BioMed Central Ltd. This is an Open Access article distributed under the terms of the Creative Commons Attribution License (http://creativecommons.org/licenses/by/2.0), which permits unrestricted use, distribution, and reproduction in any medium, provided the original work is properly cited. 


\section{Background}

Wheat is one of the major food crops grown worldwide. Its genetic improvement holds the key to achieving the levels of production necessary to meet the demands of an ever increasing world population. Keeping this in mind, the International Wheat Genome Sequencing Consortium (IWGSC; http://www.wheatgenome.org/) was established with the goal to fully sequence the wheat genome. Once achieved, the genome sequence of wheat will empower plant biologists and plant breeders worldwide to better understand the biology underlying important traits and consequently, their improvement using modern molecular biology tools.

Bread wheat (Triticum aestivum L.), which accounts for $\sim 95 \%$ of world wheat production, is evolutionarily the youngest polyploid (segmental allohexaploid) species among the cultivated crops. It has a large genome $(\sim 17$ $\mathrm{Gb})$ which is about eight times larger than that of maize (Zea mays L.) and 40 times that of rice (Oryza sativa L.) [1]. The large genome size and presence of over $80 \%$ repetitive sequences [2] makes the development of a complete physical map, a necessary first step to whole genome assembly of this species, a formidable challenge.

To partially overcome the difficulties associated with the assembly of the wheat genome, the IWGSC has approached sequencing through the construction of BAC based physical maps of individual chromosomes. Once physical contigs of acceptable size $(\sim 0.5-1 \mathrm{Mb})$ are created, markers will be developed from each contig and used to anchor them to a genetic marker scaffold. However, it has been shown that the distribution of crossing over events along the length of wheat chromosomes is uneven; very low in the centromeric regions and generally increases towards the telomeric regions [3-7]. By some estimates one-third of the wheat genome, present around the centromeres, accounts for less than $1 \%$ of the total recombination [5]. Additionally, large segmental blocks with very low recombination rates are scattered throughout the genome leading to difficulties in estimating accurate genetic to physical map distances. Thus, recombination-based mapping will not provide the necessary coverage and resolution to anchor a physical map and to estimate gap sizes between contigs. Cytogenetic stocks in wheat (e.g., ditelosomic lines and deletion bin lines) have been used for mapping and anchoring of BAC contigs [8]. However, these stocks provide limited resolution due to a large deletion size (average deletion bin is $\sim 35 \mathrm{Mb}$ ) and the inability to order markers within a given bin [8]. Radiation hybrid $(\mathrm{RH})$ mapping is a valuable alternative to recombinationbased maps and has been adopted for scaffold assembly of numerous animal genomes [9].

Radiation hybrid mapping, originally developed for mapping the human genome [10], employs radiation- induced chromosomal breaks rather than genetic recombination to map markers onto chromosomes. In principle, the likelihood of the radiation-induced DNA breaks to separate two adjacent markers increases with the increase in physical distance between the two. Therefore, the estimation of frequency of deletions/ retention between markers as well as the deletion/ co-retention patterns of various markers determines the distance between them and their order. Radiation is expected to effect the genome randomly, independent of chromosomal location; thus making the $\mathrm{RH}$ mapping a powerful tool for ordering markers and genes in any chromosomal region [11]. Additionally, the marker scoring in $\mathrm{RH}$ mapping is based on presence (retention) vs. absence (deletion) and does not require allelic polymorphism. This facilitates mapping of gene-based markers, such as ESTs, which are commonly low in polymorphism [12] and are valuable tools for interspecies comparative studies. Moreover, a very high mapping resolution $(<200 \mathrm{~Kb})$ can be achieved using relatively small number of RH lines [13-16].

Radiation hybrid mapping, in combination with recombination mapping, has contributed enormously towards whole genome physical analysis and sequence assembly of human and animal genomes [9,17]. However, there have been relatively few examples of using RH mapping in plants, which include maize $[18,19]$, barley (Hordeum vulgare L.; [20]), cotton (Gossipium hirsutum L.; [21,22]), and wheat [8,14,23-25]. Despite limited reports, $\mathrm{RH}$ mapping in plants has shown the ability to uniquely map markers that could not be resolved through traditional genetic mapping [21], and has potential to order BAC contigs into complete physical maps [25].

The D-genome, which is the smallest among the three genomes of bread wheat, is known to harbor genes/QTL for several important traits including yield [26], resistance to diseases [27], growth [28] and domestication [29]. The International Triticeae Mapping Initiative (ITMI) population was developed using W7984, a synthetic wheat derived from a cross between Altar $84 \times$ Aegilops tauschii [30], and has been used extensively to study numerous quantitative traits [26,29,31-34]. Studies on this population showed that the $\mathrm{D}$-genome of $A e$. tauschii harbors positive alleles for many important traits. However, since the D-genome is a recent evolutionary addition to the hexaploid wheat genome (> 10,000 years old), there has been limited gene flow from Ae tauschii to cultivated wheat [35]. Due to this fact, wheat varieties show limited marker polymorphism among D-genome loci [12]. Thus, attempts to develop saturated D-genome genetic maps would inevitably encounter the strenuous problem of limited polymorphic markers. Such factors laid the foundations for initiatives 
to develop physical maps of the diploid ancestral progenitor of the D-genome, in the hope that physical maps of Ae. tauschii would simplify development of physical maps of bread wheat. The accession 'AL8/78' of $A e$. tauschii was selected as it has been reported to have high genetic similarity to the D-genome of bread wheat [36]. It was used to develop numerous mapping resources including BAC libraries [37], high density gene-based genetic maps [38] and about one half million SNPs [39]. Efforts are currently underway to develop a physical map of this accession (http://wheat.pw.usda.gov/PhysicalMapping, http://www.wheatgenome.org/). However, due to non-homogenous recombination along the length of the chromosomes and the low level of polymorphism for the D-genome in the cultivated pool, genetic mapping alone is not likely to result in a saturated marker scaffold. Therefore, in the present study, a RH panel was developed for the Ae. tauschii accession AL8/78 in order to complement available data from genetic mapping and potentially produce a complete physical map of the Dgenome. Here, the development of this panel (referred to as AL8/78-DGRH ${ }_{1}$ panel) of $>1,500$ lines and its detailed molecular characterization is reported. The utility of this panel in mapping gene-based markers and BAC contigs is demonstrated and the importance of this new resource in the functional analysis of important genes is discussed.

\section{Results}

\section{Effective radiation dose and AL8/78-DGRH 1 panel development}

In order to develop a RH panel for the D-genome of $A e$. tauschii accession AL8/78, seeds of a synthetic hexaploid wheat 'SW58' (Triticum aestivum L.; $2 \mathrm{n}=42$; AABBDD) produced by crossing durum wheat cultivar 'Langdon'

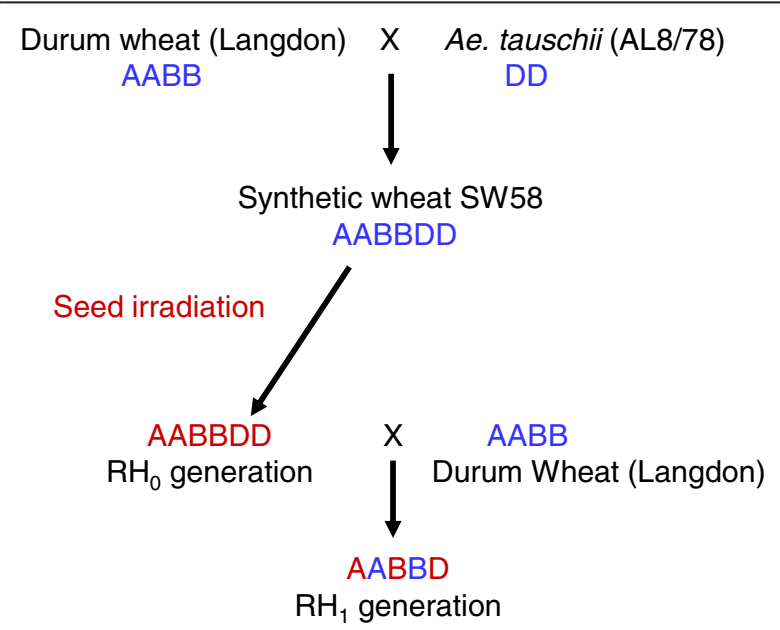

Figure 1 Schematic presentation of $\mathrm{RH}_{1}$ panel development for the D-genome of Ae. tauschii accession AL8/78.

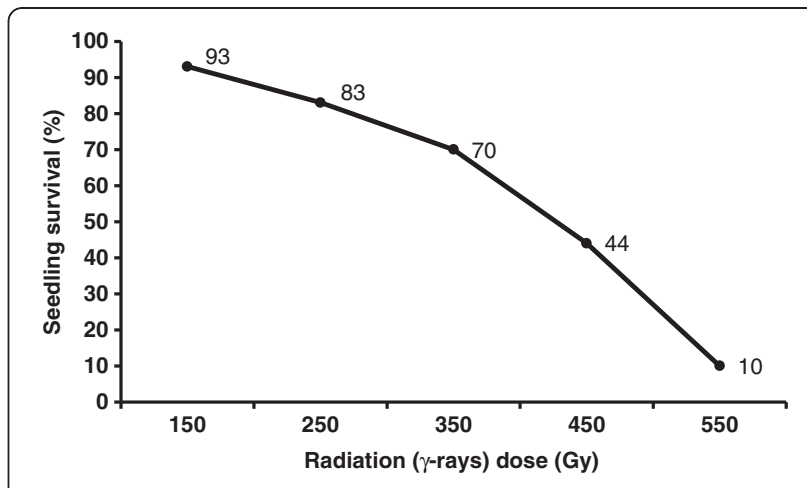

Figure 2 Effect of $\gamma$-rays on seedling survival of synthetic hexaploid wheat. Batches of 100 seeds were irradiated at various dosages and plant survival for each dose was determined as a proportion of surviving seedlings (\%) compared to the survival of plants from control seeds after 1 month.

(LDN; Triticum durum L.; 2n=28; AABB) to AL8/78 ( $T$. tauschii $\mathrm{L} ; 2 \mathrm{n}=14 ; \mathrm{DD})$ and doubling the resulting haploid progeny [40], were $\gamma$-irradiated. The resulting $\mathrm{RH}_{0}$ plants were crossed back to LDN to generate the $\mathrm{RH}_{1}$ panel for the $\mathrm{D}$-genome $\left(\mathrm{DGRH}_{1}\right.$; Figure 1$)$. The first step in $\mathrm{RH}$ panel (or any mutation population) development is the determination of optimum dose for irradiation as it may vary based on the target tissue and the genotype. In plant RH systems, the optimum dosage is the amount of irradiation that assures sufficient deletions without causing damage so serious that cannot be tolerated by the organism either during development or at the time of reproduction. To find the effective dose for the synthetic wheat SW58, batches of 100 seeds were irradiated at five different levels of $\gamma$-rays (Figure 2). Higher survival rates were observed at low doses of irradiation $\{150$ and 250 Gray (Gy) $\}$, and survival rates decreased sharply at higher doses (450 and 550 Gy; Figure 2). The survival rate at 150, 250, 350, 450, and 550 Gy was 93, 83, 70, 44 and $10 \%$, respectively. Therefore, doses of 350 Gy and 450 Gy were selected as optimal, and used to irradiate more seeds for development of the $\mathrm{DGRH}_{1}$ panel.

Initially, attempts were made to develop the population by crossing irradiated SW58 as male with LDN as female, for practical reasons related to emasculation. The planting of $\sim 5,000 \mathrm{RH}_{1}$ seeds belonging to 392 LDN $(+9) \times$ SW58 $\left({ }^{\lambda}\right)$ crosses showed very low germination $(\sim 3 \%)$. Therefore, in the next set of crosses, irradiated SW58 was used as female and LDN as male. Germination of the $\mathrm{RH}_{1}$ seeds increased to $\sim 35 \%$. To further improve the germination, mature embryos were rescued using tissue culture. Embryo rescue resulted in recovery of $>80 \%$ developing seeds in case of SW58 ( $(+)$ $\times \operatorname{LDN}\left({ }^{\lambda}\right)$ crosses. However, no improvement was observed using embryo rescue in case of LDN (q) $\times$ SW58 (ठ) crosses. 
A total of 1,510 $\mathrm{DGRH}_{1}$ plants were obtained, of which 161 belonged to LDN $\times$ SW58 cross, whereas 1,349 $\mathrm{RH}_{1}$ belonged to SW58 $\times$ LDN cross. A total of $592 \mathrm{RH}_{1}$ plants were generated from the mature $\mathrm{RH}_{1}$ seeds, and $918 \mathrm{RH}_{1}$ plants were obtained through embryo culture.

\section{Characterization of the AL8/78-DGRH 1 panel Characterization using 35 whole genome SSR markers}

To determine the extent to which the D-genome chromosomal fragments were deleted in the AL8/78$\mathrm{DGRH}_{1}$ panel, the whole panel was characterized using 35 SSR markers selected from across the seven Dgenome chromosomes. These SSR markers represent different deletion bins of each chromosome ensuring even distribution across the genome [41,42]. An average of $2.1 \%$ marker loss was observed using this set of 35 markers. An increase in average marker loss (from 1.2 to $2.4 \%)$ was observed with an increase in radiation doses from 150 to $450 \mathrm{~Gy}$ (Table 1). The average marker loss for individual chromosome in this panel ranged from $2.03 \%$ (7D) to $3.01 \%$ (4D) and was found to be homogenous by $\chi^{2}$ homogeneity test. The frequency of individual marker loss ranged from $0.89-3.95 \%$ and was heterogeneous across the genome $(p<0.01)$. However, the $x^{2}$ homogeneity test suggested that the frequency of individual marker loss in a given chromosome was homogeneous for all D-genome chromosomes except for chromosomes $1 \mathrm{D}$ and 7D. In case of chromosome 1D, two markers, cfd19 (present in the deletion bin 1DL20.41-1.00) and cfd21 (present in the deletion bin 1DS5$0.70-1.00)$ showed significantly lower marker loss $(0.89$ and $1.42 \%$ respectively) than others (3.15-3.95\%). For chromosome 7D, heterogeneity was due to marker barc1046 which showed higher marker loss (3.02\%) than other four markers (1.48-1.87\%).

In this $\mathrm{AL8} / 78-\mathrm{DGRH}_{1}$ panel, whole genome marker loss for individual $\mathrm{RH}_{1}$ lines ranged from $0-42.9 \%$, while the marker loss for individual chromosomes ranged from $0-100 \%$. There were no significant differences in the proportion of individuals with deletions among the 250, 350 and 450 Gy lines, although a slight increase was observed with the increase in dosage (Table 1). A

\section{Table 1 Characterization of the AL8/78-DGRH 1 panel}

\begin{tabular}{llll}
\hline $\begin{array}{l}\text { Dosage } \\
\text { (Gy) }\end{array}$ & $\begin{array}{l}\text { DGRH }_{\mathbf{1}} \\
\text { lines }\end{array}$ & $\begin{array}{l}\text { Frequency of } \\
\text { marker loss (\%) }\end{array}$ & $\begin{array}{l}\text { Frequency of lines } \\
\text { with deletions (\%) }\end{array}$ \\
\hline 150 & 139 & 1.2 & 14.8 \\
250 & 82 & 1.7 & 24.4 \\
350 & 676 & 1.9 & 24.5 \\
450 & 613 & 2.4 & 25.9 \\
\hline
\end{tabular}

*Data based on screening of the panel with 35 SSR markers. No lines survived $550 \mathrm{~Gy}$ irradiation dose. significantly $(p<0.05)$ lower number of individuals with deletions (14.8\%) were observed for 150 Gy lines compared to 250, 350 and 450 Gy lines. Chi-square homogeneity test showed that the proportion of lines with deletions for individual chromosome, which ranged from $4.0 \%(3 \mathrm{D})$ to $7.50 \%(1 \mathrm{D})$, was heterogeneous $(p<0.001)$ (Table 2).

Three hundred ninety-nine lines (26.4\%) in the AL8/ 78-DGRH ${ }_{1}$ panel were identified using 35 SSR markers that contained at least one marker loss (hereafter called informative lines). The selected lines had deletion frequencies from $3-42.9 \%$ for the entire D-genome, and $20-100 \%$ for individual D-genome chromosomes. Among the 399 informative lines, $15-28 \%$ of the lines had deletions for an individual D-genome chromosome (Figure 3). As compared to $2.1 \%$ marker loss frequency of the entire $\mathrm{DGRH}_{1}$ panel, this selected panel of 399 lines had an average marker loss frequency of $9.9 \%$.

\section{Characterization of a subset of AL8/78-DGRH 1 panel with larger set of markers and different marker systems}

The success of $\mathrm{RH}$ mapping depends on the deletions present in the panel. In order to have a deep insight into the deletion pattern in AL8/78-DGRH ${ }_{1}$ panel, and to study the effectiveness of a larger marker set for identifying lines with deletions, a set of $92 \mathrm{RH}_{1}$ lines from the AL8/78-DGRH ${ }_{1}$ panel was also characterized with an additional 60 repeat DNA junction markers (RJMs) spanning the whole D-genome (total of 95 markers). Increasing the number of markers for characterizing the $\mathrm{RH}_{1}$ lines also increased the proportion of informative lines (Figure 4). In this set of lines, 35 SSR markers detected $46.7 \%$ lines with deletions, while 95 markers (35 SSR and 60 RJM) detected deletions in $73.9 \%$ of the lines. A drastic increase in the number of $\mathrm{RH}_{1}$ lines with multiple chromosome breaks (Figure 5) was also observed when characterizing the $\mathrm{RH}_{1}$ lines with 95 markers. With the 35 SSR markers, $79 \%$ of the lines with deletions showed marker loss for only a single chromosome, while the remaining $21 \%$ lines have deletions for two or three chromosomes. None of the lines showed deletions for four or more chromosomes. However, characterization of the same set of lines with 95 markers showed that $69 \%$ of the lines with deletions have marker loss for 2 to 6 chromosomes. While only $31 \%$ of the lines with deletions showed marker loss for a single chromosome (Figure 5). These results clearly suggest that a majority of the lines have more deletions which were not identified when using 35 markers.

Different type of DNA markers represent different distribution patterns across the chromosome and may lead to variability in the detection of deletions. In order to check the effectiveness of different marker systems in identification of deletions in the AL8/78-DGRH ${ }_{1}$ panel, 
Table 2 Marker loss and lines with deletions for individual D-genome chromosomes in the AL8/78-DGRH panel

\begin{tabular}{lll}
\hline Chromosome & $\begin{array}{l}\text { Frequency of marker } \\
\text { loss\% (Range) }\end{array}$ & $\begin{array}{l}\text { Lines with } \\
\text { deletions (\%) }\end{array}$ \\
\hline 1D & $2.60(0.90-3.95)$ & 7.50 \\
2D & $2.84(2.07-3.20)$ & 4.90 \\
3D & $2.31(2.10-2.58)$ & 4.00 \\
4D & $3.01(2.45-3.20)$ & 4.10 \\
5D & $2.65(2.37-3.12)$ & 4.35 \\
6D & $2.88(2.22-3.20)$ & 5.80 \\
7D & $2.03(1.48-3.02)$ & 4.35 \\
\hline
\end{tabular}

the $92 \mathrm{RH}_{1}$ lines were genotyped with RJM (eight), SSR (eight) and EST (fourteen) markers belonging to chromosome 2D. The SSR and EST markers represent nearly all of the deletion bins on chromosome 2D $[42,43]$, while for RJMs, no such information was available and were picked randomly [44]. Average marker loss was significantly higher for RJMs (8.9\%) compared to SSRs (3.8\%) and ESTs (3.2\%), which were not significantly different from each other. The RJMs also showed a much wider range of marker loss (1.1-19.5\%), compared to SSRs (2.2-5.6\%) or ESTs (1.1-5.6\%). The frequency of marker loss was homogeneous for both SSR and EST markers $(\mathrm{p}<0.05)$, while it was significantly heterogeneous for RJMs $(\mathrm{p}<0.001)$.

The RJMs also detected almost three times (33.7\%) more lines with deletions compared to SSR (12\%) or EST (12\%) markers. The numbers of lines with deletions detected by SSR and EST markers were the same. The data also shows that $80 \%$ of the lines have deletions for only one of the three marker systems while only $20 \%$ lines showed deletions for 2 or 3 marker types (Figure 6).

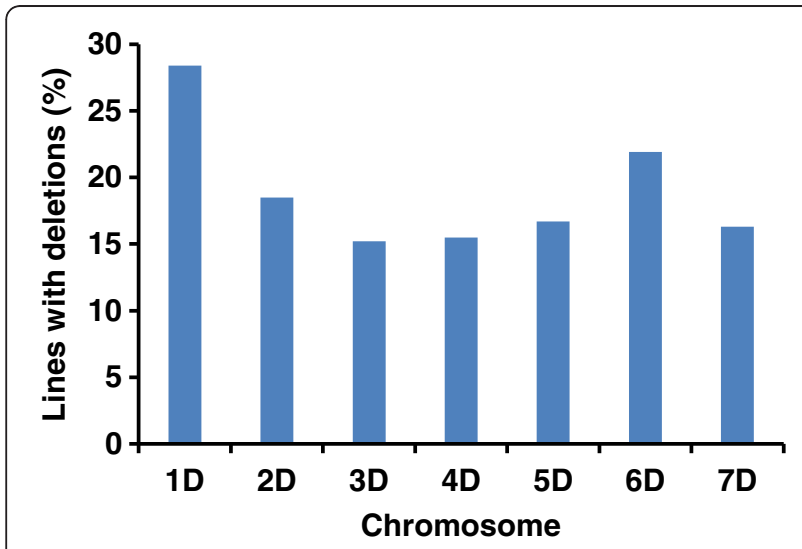

Figure 3 Distribution of informative $\mathrm{RH}$ lines for individual chromosomes in the selected $\mathrm{RH}$ panel.

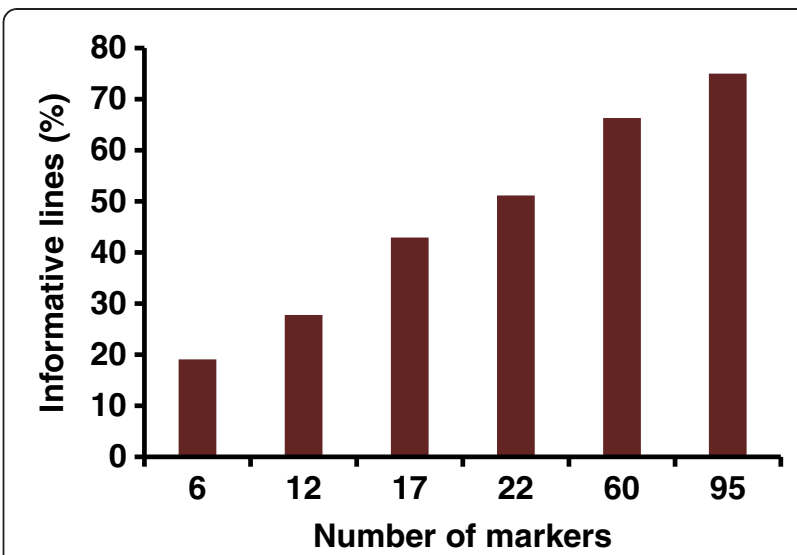

Figure 4 Effect of number of markers on the detection of lines with deletions (informative lines). The results are based on the characterization of $92 \mathrm{RH}_{1}$ lines.

\section{EST, SSR, RJM-based RH map for chromosome 2D}

The genotyping (deletion typing) data for the 30 marker loci (14 ESTs, 8 SSR and 8 RJM) on 92 AL8/78-DGRH lines was used to construct a RH map for this chromosome. With the minimum LOD score of 3, a RH map based on 25 marker loci (14 ESTs, 7 SSR and 4 RJM) was constructed (Figure 7). These 25 markers were mapped to 15 unique positions and span a distance of 453 centi-Rays (cR) (Figure 7). A comparison of the 2D $\mathrm{RH}$ map with a published genetic map [38] shows a $c M$ / $c R$ ratio of $1: 5.2$. From the $92 \mathrm{RH}_{1}$ lines genotyped, only 16 lines have deletions for the 25 markers with individual lines missing from one to 24 markers, for a total of 37 obligate breaks. This subset of 16 AL8/78-DGRH lines was able to dissect chromosome 2D into 15 distinct bins (Figure 7).

\section{Resolution of $\mathrm{AL8} / 78-\mathrm{DGRH}_{1}$ panel}

In order to check the mapping resolution of AL8/78$\mathrm{DGRH}_{1}$ panel, the entire panel was analyzed with two

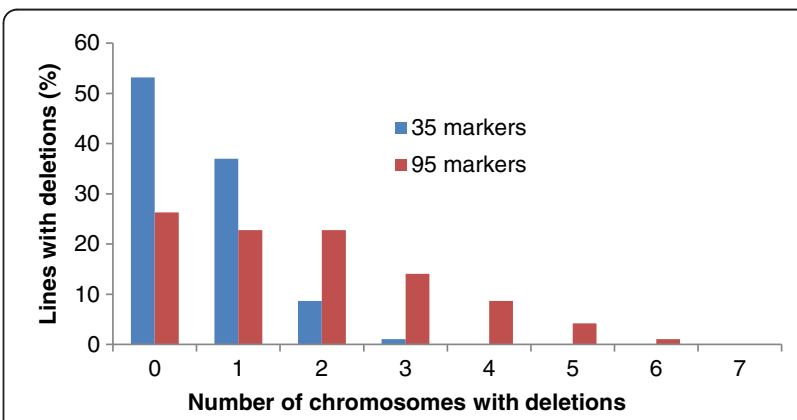

Figure $\mathbf{5}$ Effect of number of markers in detecting $\mathrm{RH}$ lines with multiple chromosome breaks. Percentage of $\mathrm{RH}_{1}$ lines with deletions for multiple chromosomes identified using two sets of different numbers of markers. The results are based on the screening of 92 lines. 


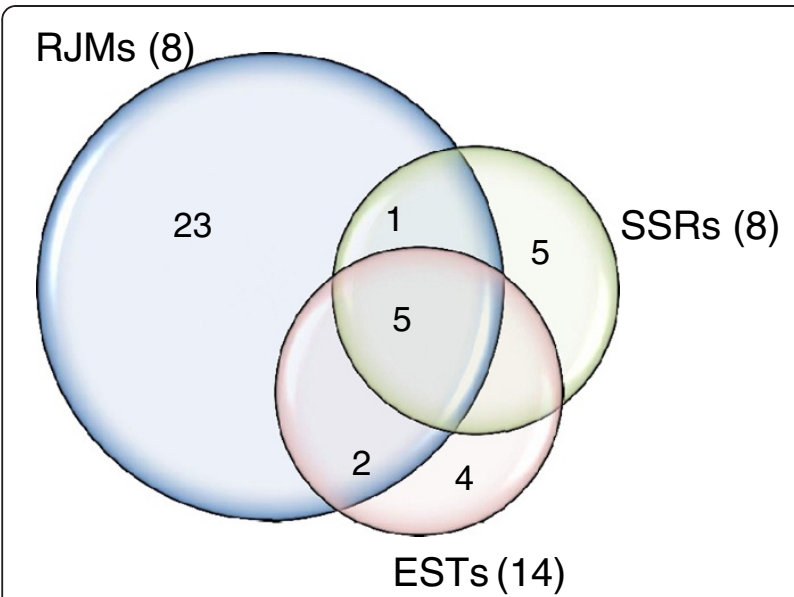

Figure 6 Comparison of RJM, EST and SSR markers in detecting deletions. Venn diagram shows the number of lines with deletions detected with each marker type in a set of 92 lines of the AL8/78$\mathrm{DGRH}_{1}$ panel. Numbers of markers used from each type are in parenthesis.

RJM markers designed from the end sequences of two BAC clones belonging to a single contig. These RJM markers were mapped to the centromeric bin of 5DL and are located $400 \mathrm{~kb}$ apart (unpublished data). Four $\mathrm{RH}$ lines among the entire panel (1,510 lines) were identified as carrying a break between these two markers, suggesting a resolution of $\sim 100 \mathrm{~kb}$. The AL8/78$\mathrm{DGRH}_{1}$ panel was further analyzed with three SSR markers physically mapped to the $1 \%$ of the most distal bin of 6DS (6DS6-0.99-1.00) which spans 3.2 Mbp region [45]. Characterization of the entire $\mathrm{RH}_{1}$ panel with these SSRs identified 23 obligate breaks in this $3.2 \mathrm{Mbp}$ region indicating a mapping resolution of $<140 \mathrm{~kb}$.

\section{Genetically effective cell number (GECN) in wheat}

The GECN was calculated as explained by Hodgdon et al. [46] with some modifications as needed for radiations hybrids (Table 3, see material and methods for more details). In order to determine the GECN in the present study, 35 SSR marker (5 from each D-genome chromosome) based deletion data for $339 \mathrm{DGRH}_{1}$ plants belonging to $29 \mathrm{RH}_{1}$ families was used to calculate the segregation ratio for each unique deletion mutation. Deletion mutations for single chromosomes were treated separately. The number of progenies represented in an $\mathrm{RH}_{1}$ family ranged from 10 to 17 . In total, 73 data sets were used to calculate the GECN. Based on the segregation ratio of deletions $v s$. wild type, the GECN in these families ranged from 1.4 to 8.5. However, the concept of GECN is more valid as anerage [46,47] and the average GECN was calculated to be 5.25. The average GECN computed on the basis of deletions for individual chromosomes was not significantly different (Table 4). So, this data suggests that GECN in wheat is 5 or more. However, at higher GECN, a large number of progeny families are needed to identify all possible deletions.

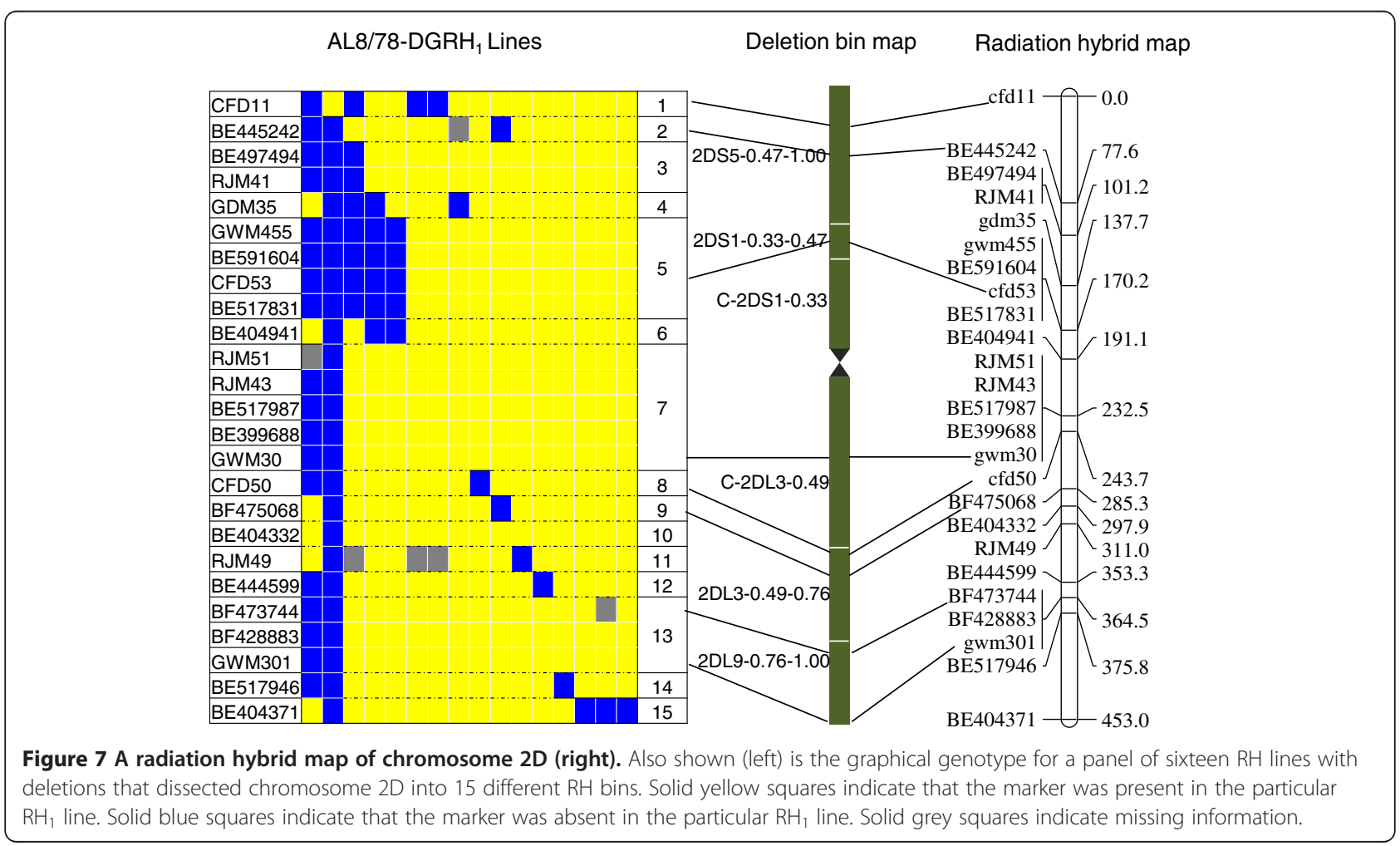


Table 3 Genetically effective cell number (GECN)

\begin{tabular}{lll}
\hline Segregation ratio & $\mathbf{G E C N}$ \\
\hline $\mathbf{M}_{\mathbf{2}}$ population & $\mathbf{R H}_{\mathbf{1}}$ population & \\
\hline $3: 1$ & $1: 1$ & 1 \\
$7: 1$ & $3: 1$ & 2 \\
$11: 1$ & $5: 1$ & 3 \\
$15: 1$ & $7: 1$ & 4 \\
$19: 1$ & $9: 1$ & 5 \\
$23: 1$ & $11: 1$ & 6 \\
$27: 1$ & $13: 1$ & 7 \\
$31: 1$ & $15: 1$ & 8 \\
\hline
\end{tabular}

\section{Discussion}

Despite the fact that sequencing costs have reduced significantly in the past few years and may continue to do so in the future, short-read shotgun data without annotation does not provide the information needed for analysis of genetic and linkage data and its functional implications. Moreover, development of polymorphic markers and mapping of millions of contigs generated by next generation sequencing is prohibitively expensive despite the development of high-throughput genotyping platforms. Data from animal systems indicate that survey sequencing (1-2X genome coverage) combined with high resolution $\mathrm{RH}$ maps deliver a comprehensive map of over 10,000 loci in which over $90 \%$ of the markers were ordered [48]. When applied to plants, this combined approach can provide a dense physical map that may be used for crop improvement and selection, map-based gene cloning, and comparative analysis of various species. However, RH mapping relies heavily on the availability of an adequate $\mathrm{RH}$ population rich in detectable deletions. Wheat is an allohexaploid species, meaning that it contains three sets of homoeoloci for each gene and deletions in one or more of these loci can be potentially buffered by the others. Viable plants carrying large deletions can be obtained as demonstrated by the production of the wheat deletion bin genetic stocks [49]. The AL8/78-DGRH ${ }_{1}$ is a whole genome panel designed for the $\mathrm{RH}$ mapping of all seven D-genome chromosomes of Ae. tauschii.

\section{Radiation dose for development of RH panel}

The selection of an appropriate dose for irradiation is an important step in the development of radiation hybrids in plants. Different genotypes may respond differently to radiation treatments. The hexaploid wheat cultivar Chinese Spring showed a survival rate of $21 \%$ when irradiated with 350 Gy of $\gamma$-rays [24] compared to $70 \%$ survival observed for the synthetic hexaploid wheat SW58 irradiated at the same dose. It was also observed that the seeds of LDN showed significantly higher survival compared to another durum wheat cultivar (both tetraploid) when irradiated with 350 Gy (unpublished data). Since SW58 contains the AB genome from LDN [40], a better response of SW58 and LDN to $\gamma$-radiation suggests that LDN genome may be more tolerant to radiation damage. Although the biological basis of irradiation tolerance in these lines is not known, the results of the present study suggests that for any $\mathrm{RH}$ panel, it is important to optimize the radiation dosage for the particular genotype.

The selection of an appropriate irradiation dose is also crucial as previous studies have observed an increased marker loss and mapping resolution with the increase in dose of $\gamma$-irradiation [18,22,24]. However, it is impossible with the $\mathrm{RH}$ approach in plants to go beyond a certain level of radiation as the increase in dosage leads to decrease in seed germination, plant survival, fertility and poor vigor $[14,18,24]$. A large decrease in plant survival above 350 Gy and lack of plant recovery from the 550 Gy irradiated seeds was observed in this study. This is likely due to the fact that the irradiated cells go through mitotic cell division and highly fragmented nuclei are not likely to survive the selection during plant development.

Based on the findings, the 450 Gy was the best possible dose for AL8/78-DGRH 1 panel development. Additionally, as the higher doses of radiation cause higher number of breaks and rearrangements [18,22], a larger number of markers will be needed to develop linkage groups [9]. The 350 Gy $\mathrm{RH}$ lines were developed to complement the 450 Gy RH lines as the combination of $\mathrm{RH}$ panels of different resolution can yield a better contiguous map [50].

Effect of crossing scheme and role of genome imprinting The methodology presented here to develop a $\mathrm{RH}$ panel for the D-genome of Ae. tauschii involves two interspecific hybridizations. First, the synthetic hexaploid wheat SW58 (AABBDD) was developed by crossing tetraploid durum wheat LDN (AABB) to A. tauschii (DD) accession AL8/78 [40]. Secondly, the irradiated SW58 was

Table 4 Average GECN calculated from deletions on different chromosomes in the $\mathrm{RH}_{\mathbf{1}}$ families

\begin{tabular}{cccc}
\hline Chromosome & Average GECN & Range & $\mathbf{R H}_{\mathbf{1}}$ families studied \\
\hline 1D & 5.2 & $1.8-8.5$ & 21 \\
2D & 5.5 & $5.0-8.5$ & 9 \\
3D & 5.5 & $1.7-8.5$ & 7 \\
4D & 5.4 & $2.5-8.5$ & 9 \\
5D & 4.7 & $1.4-8.5$ & 9 \\
6D & 5.3 & $2.5-7.0$ & 12 \\
7D & 5.4 & $2.8-7.0$ & 6 \\
\hline
\end{tabular}


crossed to LDN and pentaploid $\mathrm{DGRH}_{1}$ seeds were obtained, which allow for an exclusive identification of deletions in the $\mathrm{D}$-genome of Ae. tauschii.

The $F_{1}$ seeds developed from the interspecific crosses mostly show low germination and poor vigor that is attributed to possible crossing barriers. The most common post-zygotic reason for failure of wide hybridization is an embryo abortion due to poor endosperm development. The AL8/78-DGRH 1 seeds developed from the reciprocal crosses $(\mathrm{LDN} \times$ SW58 and SW58 $\times$ LDN) showed varying degree of endosperm development. The endosperm development was poor in most seeds when irradiated SW58 was used as male. The endosperm appeared more developed when SW58 was used as a female. This could be a reason for the differences observed in germination of AL8/78-DGRH ${ }_{1}$ seeds belonging to reciprocal crosses $(\sim 3 \% v s$. $\sim 80 \%)$. This difference could be attributed to genomic imprinting in endosperm resulting from differences in the ploidy levels of the two parental genotypes [51-53]. Endosperm is well developed whenever it is diploid [AAABBBDD in case of SW58 (q) $\left.\times \operatorname{LDN}\left(\delta^{\lambda}\right)\right]$ for the whole set of extra seven chromosomes (DD in our case) and is wrinkled when it is haploid for the D chromosomes [AAABBBD in case of LDN $\left(\right.$ ( ) $\left.\times \operatorname{SW58}\left(\widehat{O}^{\lambda}\right)\right][54,55]$. Although there are chances that homologous chromosomes of the D-genome have deletions, it is highly unlikely that both have the same deletion, therefore, endosperm containing a pair of Dgenome chromosomes even with deletions has a better chance of development. The differences in endosperm may also be due to genomic imprinting which is the result of monoallelic gene expression in a parentof-origin-dependent manner [56]. In Arabidopsis embryogenesis, there is a strong evidence of maternal epigenetic pathways controlling the parental contributions in plant embryos [57]. Additionally, in cases of interspecific crosses, the correct balance between maternal and paternal genomes is disturbed as in the cross between durum and synthetic hexaploid wheat, and crosses between species with different ploidy levels, leading to significant differences in the success of reciprocal crosses [53].

\section{GECN and its implication on RH panel development}

When irradiating seeds, the diploid germline cells of the fully developed embryo are the radiation target. So, if the GECN is greater than one, the plant germinating from the $\mathrm{M}_{1}$ seed $\left(\mathrm{RH}_{0}\right.$ seed in case of $\left.\mathrm{RHs}\right)$ will be chimeric because independent mutations occur in each of the cells. The GECN has been reported to vary between different species. A GECN of two in Arabidopsis thaliana [58], Nicotiana plumbaginifolia [59-61], and soybean [62], four in flax [63], four or more in corn $[47,64]$, and six in barley [46] have been reported. To our knowledge, this is the first time that the GECN is calculated from a $\mathrm{RH}_{1}$ population and for wheat. The information about GECN of the species under study is important in any $\mathrm{RH}$ or mutation-based experiments, as it can be used to estimate the rate of recovered deletions or other types of mutations. The probability of recovering a $\mathrm{RH}$ line with a deletion at a given locus in any $\mathrm{RH}$ family (or a mutant in $\mathrm{M}_{2}$ family) depends upon the number of plants screened from that family, the GECN for that particular plant species, and on the frequency of the mutation/deletion. The probability increases with the number of plants screened and decreases as the GECN increases. The AL8/78-DGRH ${ }_{1}$ panel represented $312 \mathrm{RH}_{1}$ families, with an average of 4.8 siblings per family. With a GECN $=5$ and screening of $\sim 5$ lines per $\mathrm{RH}_{1}$ family, approximately $40 \%$ of the deletions available in this panel for the 35 SSR marker loci were identified. The GECN of 5 indicates that at least 30 seeds in an $\mathrm{RH}_{1}$ family need to be analyzed to recover the same mutation at 95\% confidence. Therefore, the GECN information for wheat is important in selecting informative lines from an $\mathrm{RH}_{1}$ population or identifying mutants in an $\mathrm{M}_{2}$ population. In wheat RH mapping, GECN of $\geq 5$ offers an additional advantage of identifying multiple $\mathrm{RH}$ lines with different deletion patterns from the same $\mathrm{RH}_{1}$ family developed by a single cross. The $399 \mathrm{RH}_{1}$ lines showing deletion(s) for one or more of the 35 SSR markers belonged to 211 crosses and showed up to five unique genotypes per cross. This indicates that more informative lines can be obtained from few crosses, thus, reducing the efforts required for developing a RH panel.

\section{Distribution of marker deletions in $\mathrm{RHs}$}

It has been estimated that less than $1 \%$ of recombination occurs in $\sim 30 \%$ of the proximal regions of wheat chromosomes [5]. This means that map-based cloning of genes in the recombination-poor regions is not feasible utilizing the traditional recombination based approach. The uneven distribution of recombination also leads to variation in genetic to physical distances across the chromosome. RH mapping uses retention/loss frequency as a result of breaks caused by radiations, which are expected to be random. Therefore, the mapping power of RHs is expected to be uniform across the length of a given chromosome.

The five markers selected from each chromosome mostly represented different deletion bins and were genetically far from one another. The mapping data of these markers shows that the marker loss frequency within a chromosome is homogeneous for all chromosomes except for chromosome 1D and 7D. For 1D the heterogeneity was due to two markers showing higher retention. Similar results have also been reported earlier for the markers present in the same deletion bin (1DS50.70-1.00 and 1DL2-0.41-1.00) [14]. This could be due 
to the presence of critical gene(s) essential for the plant survival in this region leading to comparable lower observed marker loss than other chromosomal regions.

The distribution of deletions along a chromosome can be viewed from the five markers of chromosome 4D which represented different physical positions including centromeric bins of both long (C-4DL9-0.31) and short arm (C-4DS1-0.53) as well as sub-telomeric (4DS1-0.53$0.67)$ and telomeric region (4DL12-0.71-1.00). No preferential loss of markers for any region was observed. Similar results have been reported in maize [18], wheat [24], and cotton [22]. These results suggest that a uniform mapping resolution across the genome can be achieved with RHs, including the low recombination centromeric regions, which is not possible with genetic mapping. However, studies based on larger number of randomly distributed molecular markers of different types will provide a more detailed picture of the distribution of deletions along the length of the chromosome, and will help to determine, whether or not, the radiationinduced breakage is effected by chromosome structure or any other biological phenomenon.

\section{Selected RH lines for developing a high-resolution physical map of D-genome}

The success of RH mapping depends on marker loss/retention frequency in a panel. Simulation studies have suggested that a retention/loss frequency of $50 \%$ would be optimal [65]. However, most RH mapping studies conducted in animals showed average retention frequency of about $20-30 \%$ [9]. The marker loss observed in this population was much lower than what was observed in animals, but was comparable to that earlier reported in wheat [24]. In plants, it is not possible to obtain the hybrids with marker loss comparable to human or animal RH panels as viable and fertile plants from the irradiated seeds need to be recovered.

The informative panel of 399 lines selected in this study has an average marker loss about five times higher (9.9\%) than the whole unselected $\mathrm{DGRH}_{1}$ panel (2.1\%). The effectiveness of this selection strategy was tested by screening a subset of 92 random $\mathrm{RH}_{1}$ lines with 60 additional markers. However, a high correlation $(\mathrm{r}=0.94)$ was observed between deletion frequency of the $\mathrm{RH}$ lines based on screening with a small (35) and large set (95) of markers. Moreover, almost all the lines (>92\%) detected with multiple chromosome $(>3)$ breaks using the larger set were also included in the set of informative lines identified using only 35 markers. This shows that the RH lines with deletions identified using few (35) markers have multiple deletions across the genome. Thus, the strategy to select highly informative lines using few markers from across the whole genome is as effective as selection based on almost three times larger marker set. However, selection with a larger set of markers detected additional informative lines, suggesting that the these lines possess smaller and unique deletions, which could be extremely useful when the purpose is to fine map a particular genomic region.

\section{Combination of different marker systems for a better contiguous map}

Different marker systems represent different types of DNA sequences and potentially different distributions in the genome. Three different types of markers (RJM, SSR, EST) were used to characterize a subset of AL8/78$\mathrm{DGRH}_{1}$ panel. The marker loss for RJMs was much higher and identified almost three times more lines with deletions as compared to SSRs or ESTs. A simple explanation would be that ESTs and SSRs mainly represent gene rich regions [66], potentially more prone to cause loss in vitality when deleted as compared to RJMs which usually span the inter-genic repetitive space [44]. Any deletion in the gene clusters will reduce the chances of survival of the particular RH line, leading to the detection of fewer lines with deletions among the surviving plants. Comparatively, plants with deletions in the repetitive DNA have more chances of survival. However, repetitive DNA is present in both genic and inter-genic regions $[2,67]$ which could be a possible explanation for the wide range of marker loss (1.1-19.5\%) observed for RJMs. The other explanation could be found in the specific marker design. RJMs are designed to span unique retrotransposon insertion sites. These insertion sites are typically characterized by a chromatin state more susceptible to DNA breakage [68]. Recent findings indicate that radiation damage and the subsequent DNA repair might also prefer these exposed chromatin regions to cause breakage [25]. This would also explain why RJMs have the tendency to be deleted with higher frequency. Similarly, the large amount of variation in chromatin state in intergenic regions would explain the wide range of marker loss for RJMs.

The abundance and uniform distribution of retrotransposons across the genome makes RJMs [44] ideal candidates for high density RH mapping. SSR markers, on the other hand, have been used extensively in wheat for the construction of genetic maps and the identification of marker-trait associations [69], http://wheat.pw.usda.gov. Therefore, SSRs can serve as excellent anchor points for mapping anonymous markers and as a linking bridge between the available genetic information and the high density RH maps. Gene-based markers like ESTs are an efficient tool for inter-species comparative genome analysis $[15,38]$.

The use of different type of markers to characterize a subset of AL8/78-DGRH 1 panel showed that deletions in the majority of the lines $(80 \%)$ were detected by either of 
the three marker type. Similarly, a recent study in wheat reporting the first physical map of a wheat chromosome, which used different classes of marker types to anchor BAC contigs, observed that $\sim 70 \%$ of the contigs were anchored with only one marker type [8]. These observations clearly suggest that different marker classes have different advantages for genomic research and also cover different regions of the genome. Therefore, a combination of various markers is better suited to obtain a complete RH/physical map for whole genome assembly.

\section{Combining RH and genetic mapping: A better approach for genome mapping}

Dependence of genetic mapping on recombination makes it difficult to conduct map-based cloning of genes in the recombination-poor regions. The requirement of polymorphism for genetic mapping also makes it more difficult to map gene-based markers [12] which are invaluable tools for comparative studies across species. The selection pressure tends to remove any nonadvantageous allelic polymorphisms in the gene space making gene-based markers highly monomorphic among individuals of the same species. In wheat, 9.9\% polymorphism was observed for EST-derived SSRs compared to $35.5 \%$ polymorphism observed in case of genomic SSRs [12].

The presence/absence aspect of RH mapping which do not require genetic polymorphism may help in drastically increasing the number of mapped markers including gene-based markers. From the 14 ESTs mapped on the chromosome 2D using 92 random $\mathrm{RH}_{1}$ lines (only 16 were critical lines), only six could be mapped in a diploid bi-parental population of $572 \mathrm{~F}_{2}$ plants [38], suggesting that RH mapping has the potential to increase the number of mapped markers using comparatively fewer lines. The 2D-RH map also provided 5.2 fold higher resolution $(c M / c R$ ratio of 1:5.2) than the genetic map [38], confirming that $\mathrm{RH}$ mapping indeed provides higher resolution than genetic mapping. At the same time, the availability of hundreds of genetic maps and genetically mapped loci in wheat [69] is an asset and this information may provide better consensus maps. In addition, the genetic maps could easily be used for identifying QTL/genes for any phenotypic trait segregating in that population. Therefore, $\mathrm{RH}$ mapping has the potential to complement a genetic mapping approach by mapping the markers in low recombination regions and making it possible to map a larger amount of monomorphic genebased markers.

\section{Radiation hybrids for BAC contigs assembly}

The IWGSC has established a clear road map to achieve the complete sequencing of the wheat genome [70]. This includes the creation of high quality physical maps for each of the 21 chromosomes, individually. In this direction, the first physical map of a single chromosome was reported for $3 \mathrm{~B}$ [8]. The authors described the assembly of 1,036 contigs with an average size of $0.78 \mathrm{Mb}$, covering $\sim 82 \%$ of the $3 \mathrm{~B}$ chromosome. Although 1,443 molecular markers were developed from the BAC contigs, not all were polymorphic or could be uniquely mapped into a marker scaffold despite using information from 13 genetic mapping populations, especially for those regions that have limited recombination [8]. Apparently the use of genetic maps alone might not be enough to generate sufficient resolution for the IWGSC initiatives [8] due to non-uniform distribution of recombinants along the length of the chromosome and low level of polymorphism in bi-parental genetic populations. In humans [71,72] and animals [73-77], RH mapping played a major role in the contig assembly leading to whole genome sequencing [17].

Considering the success of $\mathrm{RH}$ approach in human and animal genome assembly, the AL8/78-DGRH ${ }_{1}$ panel was made to help the assembly of BAC contigs from the wheat D-genome project. Although an effort similar in scale to the one described here is not available as reference for the plant kingdom, preliminary studies suggested that a map resolution of $\sim 200 \mathrm{~kb}$ is achievable with $\mathrm{RH}$ in plants $[8,23,25]$. Similar level of resolution was achieved in the AL8/78-DGRH ${ }_{1}$ panel as indicated by analysis with a set of markers for which the physical distance was known.

Past studies in plants have reported the detection of up to thirteen deletions for a single chromosome in an individual $\mathrm{RH}_{1}$ line $[14,18,24,25]$. However, as observed in the present study and also reported earlier [23] the number of detectable deletions may increase by genotyping the panel with more markers. Assuming an average of 3 random deletions for a particular chromosome and BAC contigs of a size observed by Paux et al. [8] for 3B (482 kb), the selected set of 399 highly informative AL8/ 78-DGRH ${ }_{1}$ lines is adequate to anchor and order all the BAC contigs of any D-genome chromosome.

The resources generated here provide a foundation for the development of next generation, high-density RH maps incorporating thousands of marker including SSRs, RJMs, ESTs etc. These maps will provide a marker scaffold to develop complete physical maps leading to the final sequence assembly of the seven wheat Dgenome chromosomes.

\section{Potential applications of RHs for functional genomics}

Cytogenetic stocks in wheat have been used extensively to study genes/phenotypes associated with a particular chromosome or its segment $[78,79]$. However, due to the availability of limited number of these lines, this approach offers an even lower resolution than genetic mapping. The association of phenotypic and genotypic 
data, both recorded on $\mathrm{RH}_{1}$ lines developed during the present study, may help assign the phenotype to genomic deletions as is done in case of genetic mapping or deletion bin mapping [78,79], but at much higher resolution. This has been successfully illustrated by mapping the genes in low recombination regions in wheat $[14,80]$.

The first-generation radiation hybrids $\left(\mathrm{RH}_{1 \mathrm{~s}}\right)$ contain D-genome chromosomes with rearrangements in a monosomic condition. Variation is expected in the transmission of D-genome chromosomes to subsequent generations $[81,82]$. It also means that it will not be possible to replicate the phenotypic data recorded on the $\mathrm{DGRH}_{1}$ lines, unless the segregating lines are confirmed for the presence of a particular chromosome with the phenotypes. However, as an alternative RH maps can be used to identify the $\mathrm{RH}_{1}$ lines showing deletions for the markers associated with any particular trait of interest. Using this information, the parental $\mathrm{M}_{2}$ families of specific $\mathrm{RH}_{1}$ plants may be used to select homozygous and stable deletion mutants for the flanking markers (and the markers in between) of the gene/QTL. A set of such overlapping deletion lines and their trait data will help in physically placing the gene in a small segment of the chromosome. In a similar fashion, this approach may also be used for understanding the phenotypes associated with known genes (reverse genetics) by screening the DNA of the whole set of AL8/78- $\mathrm{DGRH}_{1}$ lines generated during the present study, for deletions of a particular gene sequence and then studying their parental $\mathrm{M}_{2} \mathrm{~s}$.

\section{Conclusions}

Radiation hybrid mapping is an important tool for mapping/cloning genes in recombination poor regions [14] and developing a marker scaffold for whole genome assembly $[8,25]$ of important crops like wheat with complex and highly repetitive genomes. A RH panel was developed for the D-genome of Ae. tauschii accession AL8/78 (AL8/78-DGRH $\left.{ }_{1}\right)$ and is the first reported for any wild ancestor of a cultivated plant species. Characterization of this panel with markers covering whole $\mathrm{D}$-genome provided insight into various aspects of RH mapping which will be helpful in implementing similar tactics for important genomic studies in other plant species. Genetically effective cell number which has significant importance in developing RH panel was estimated for wheat for the first time. The results showed that the marker loss was independent of chromosome location and thus, more uniform resolution can be expected along the length of the chromosome including low recombination regions. Different marker systems mostly detected different RH lines with deletion, suggesting that a combination of marker systems is required to achieve a complete physical map. The results also showed that a much higher mapping resolution can be achieved with few informative RH lines compared to a larger recombinant population. Overall, the mapping resolution of this $\mathrm{RH}$ panel was estimated to be $\sim 140 \mathrm{~kb}$ which is sufficient enough to align the available BAC contigs. The panel also showed a great potential for mapping gene based markers. Finally, a set of 399 most informative $\mathrm{RH}$ lines was also identified. This AL8/78$\mathrm{DGRH}_{1}$ panel will be an invaluable resource for developing a complete marker scaffold for the whole genome sequence assembly as well as fine mapping and functional characterization of genes and gene networks present on the D-genome.

\section{Methods}

Seed material and radiation treatment

The present study used a synthetic hexaploid wheat line SW58 (Triticum aestivum L.; $2 \mathrm{n}=42$; AABBDD) and a durum wheat cultivar Langdon (LDN; Triticum durum L.; $2 \mathrm{n}=28 ; \mathrm{AABB})$. SW58 was previously developed from a cross of LDN and Ae. tauschii (DD) accession AL8/78 [40]. Seeds from SW58 were equilibrated to $13 \%$ moisture as described earlier [14] and were $\gamma$-irradiated at five different doses $\{150,250,350,450$ and 550 Grays (Gy)\}. The seeds were planted in the greenhouse after irradiation. Plant survival for each irradiation dose was determined as a proportion of surviving seedlings compared to the survival of plants from control seeds (nonirradiated SW58 seeds) one month after sowing.

\section{Population development \\ Crossing scheme}

After irradiation, the seeds $\left(\mathrm{RH}_{0}\right)$ were pre-germinated in petri dishes. After one week of germination, the seedlings were transferred to six inch clay pots containing Sunshine Mix \#1 (Sun Gro Horticulture, Vancouver, Canada) augmented with soil. Plants were grown in a greenhouse (16-h light cycle; $15^{\circ}-25^{\circ} \mathrm{C}$; water, pesticide and fertilizer applications as required). $\mathrm{RH}_{0}$ plants were crossed to normal LDN to obtain the D-genome $\mathrm{RH}_{1}$ $\left(\mathrm{AL} 8 / 78-\mathrm{DGRH}_{1}\right)$ seeds (Figure 1). A 2,4-D hormone solution $(213.05 \mathrm{mg} / \mathrm{L}$ of $2,4-\mathrm{D}, 80 \mu \mathrm{l} / \mathrm{L}$ of Tween 80 , $50 \mathrm{mg} / \mathrm{L}$ of $\mathrm{GA}_{3}, \mathrm{pH} 10.36$ ) was applied to the crossed spikes at 24 and 48 hours post pollination. After pollination, either the developing embryos were rescued from the growing $\mathrm{RH}_{1}$ seeds to obtain the $\mathrm{RH}_{1}$ plants, or the mature $\mathrm{RH}_{1}$ seeds were harvested and directly planted in the greenhouse to obtain the $\mathrm{RH}_{1}$ plants. Multiple $\mathrm{RH}_{1}$ seeds from the same cross were also planted to maximize the number of $\mathrm{RH}$ lines with different deletion events. All the $\mathrm{RH}_{1}$ plants from the same cross represent an $\mathrm{RH}_{1}$ family. 


\section{Embryo rescue}

The $\mathrm{RH}_{1}$ seeds were collected at 21-28 days after pollination. Seeds were surface-sterilized under a laminar flow hood by immersion in $70 \%(\mathrm{v} / \mathrm{v})$ ethanol for $1 \mathrm{~min}$., followed by $20 \%(\mathrm{v} / \mathrm{v})$ household bleach for $5 \mathrm{~min}$. The seeds were then rinsed three times for $5 \mathrm{~min}$. each with sterilized water. Embryos were excised from the seeds under a dissecting microscope and placed on MS media [4.4 g/L of MS basal salt (Sigma-Aldrich, St. Louis, MO; M5519 with vitamins), $50 \mathrm{~g} / \mathrm{L}$ of sucrose (Sigma-Aldrich, St. Louis, MO), $3.5 \mathrm{~g} / \mathrm{L}$ of phyta gel (Sigma-Aldrich, St. Louis, MO), $\mathrm{pH}$ 5.7] in petri dishes. The petri dishes were sealed and kept at room temperature in the dark for embryo germination. After germination, embryos were kept under a 16-hours light cycle at room temperature. At the two leaf stage, the media was washed off the roots and the germinating seedlings were transplanted into a 96-well tray containing sunshine mix. The plants were transferred to soil beds after 15-20 days and grown under greenhouse conditions as described earlier.

DNA markers for characterization of AL8/78-DGRH1 panel Three different types of DNA marker were used in this study: simple sequence repeat (SSR), repeat DNA junction marker (RJM) and expressed sequence tag (EST). The SSR and EST markers were selected based on their known genetic or physical location [41-43]. For RJMs, only chromosome assignments were available and therefore, were picked randomly from different chromosomes [44]. The D-genome specificity of the markers was verified by positive amplification in hexaploid DNA (SW58; AABBDD) and no amplification in tetraploid wheat DNA (LDN; $\mathrm{AABB})$. Since $\mathrm{RH}$ mapping is based on a presence/absence assay, the markers that amplified only a single D-genome specific fragment were multiplexed with an A or B genome-specific marker to provide a control against PCR failure. This internal multiplex control distinguished between absence of a marker band due to PCR failure (no bands present) and the deletion of the marker loci due to irradiation (only the control band present).

A total of 1,510 lines from the AL8/78-DGRH panel $_{1}$ were genotyped with 35 SSR markers, 5 markers from each of the seven D-genome chromosomes [41,42]. Additionally, $92 \mathrm{RH}_{1}$ lines (one 96 well plate with 4 parental genotypes for genotyping convenience) were further characterized with an additional 78 markers, which included 4. SSRs and 14 ESTs located on chromosome $2 \mathrm{D}$ and 60 RJMs representing all seven chromosomes of the D-genome [44].

To estimate the mapping resolution of the AL8/78$\mathrm{DGRH}_{1}$ panel, two RJMs were developed from the end sequences of two BACs separated by ca. $400 \mathrm{~Kb}$ physical distance (unpublished data). Marker primers were designed using RJPrimers [83] and synthesized by
Sigma-Aldrich (St. Louis, MO). The AL8/78-DGRH panel was then genotyped using these two RJMs to identify obligate breaks between them to provide an estimate of the physical resolution of the AL8/78-DGRH 1 panel. Similarly, three SSR markers physically mapped to the $1 \%$ of the most distal bin of 6DS (6DS6-0.99-1.00) and covering a region of $\sim 3.2 \mathrm{Mbp}$ [45] were also used to identify obligate breaks and confirm the mapping resolution of the AL8/78-DGRH 1 panel.

\section{DNA extraction and PCR analysis}

DNA from parental genotypes and $\mathrm{RH}_{1}$ plants was extracted from lyophilized leaf tissue of one month-old plants as described by Guidet et al. [84]. PCR amplification was carried out in $15 \mu \mathrm{l}$ reactions containing $1 \mathrm{x}$ PCR buffer, $1.5 \mathrm{mM}$ of $\mathrm{MgCl}_{2}, 200 \mathrm{nM}$ of each dNTP, $250 \mathrm{nM}$ of each primer, and 1.0 unit of Taq DNA polymerase. SSR and RJM markers were amplified in a thermocycler programed for initial denaturation at $94^{\circ} \mathrm{C}$ for 3 min.; 35-45 cycles of $94^{\circ} \mathrm{C}$ for $45 \mathrm{sec}$., $51^{\circ}, 55^{\circ}, 58^{\circ}$ or $60^{\circ} \mathrm{C}$ (depending on annealing temperature) for $45 \mathrm{sec}$, and $72^{\circ} \mathrm{C}$ for 1 min.; followed by final extension at $72^{\circ} \mathrm{C}$ for $10 \mathrm{~min}$. For EST markers a touchdown PCR was carried out with initial denaturation at $94^{\circ} \mathrm{C}$ for 5 min., 10 cycles of $94^{\circ} \mathrm{C}$ for $30 \mathrm{sec}$. $65^{\circ} \mathrm{C}$ for $30 \mathrm{sec}$. (reduced by $0.5^{\circ} \mathrm{C}$ each cycle) and $72^{\circ} \mathrm{C}$ for $1 \mathrm{~min}$. followed by another 35 cycles of same conditions with annealing temperature of $60^{\circ} \mathrm{C}$. A final extension was carried out at $72^{\circ} \mathrm{C}$ for $10 \mathrm{~min}$. PCR products were separated on $3.0 \% \mathrm{w} / \mathrm{v}$ agarose gels in $0.5 \mathrm{X}$ TBE.

\section{Data analysis and RH map construction}

The AL8/78-DGRH ${ }_{1}$ panel was scored for marker presence or absence. Ambiguous results in all cases were recorded as a missing data. Marker loss or retention frequency was defined as the proportion of $\mathrm{RH}$ lines with marker lost/retained in the AL8/78-DGRH ${ }_{1}$ panel. Chi-square tests were used to find differences in marker loss between radiation dosages, and to determine the homogeneity of marker loss between and within chromosomes.

A total of 30 markers (8 SSR, 8 RJM and 14 EST) belonging to chromosome $2 \mathrm{D}$ and screened on 92 lines

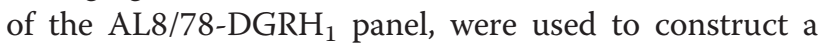
2D RH map. The RH map was generated using Carthagene 1.2.2 [85]. Six SSR markers were first anchored based on available genetic information and deletion bin location $[41,42]$. Remaining markers with known bin information were then added to the anchored markers by mapping each bin separately. Every possible combination was attempted for each marker, and the lowest distance map was used as the framework map. The remaining markers were placed onto the framework map using the buildfw function through iterative analysis [25,86]. Two iterations were needed for this data set. Markers were 
assigned to intervals between two anchor markers using the command buildfw with LOD score of 3 . These assigned markers, two initial inner and two outer anchor markers of the framework map were then mapped by Carthagene using build10, greedy search, genetic algorithm, annealing, flips, and polish functions. All markers mapped between two anchor markers underlying a specific interval were merged into the new framework map. All other markers were discarded and reused in the following iteration.

\section{Calculation of genetically effective cell number (GECN)}

In a mature embryo, only a few meristematic cells give rise to the plant's flowering parts. These cells (germ line) at the time of mutation induction which develop into an inflorescence structure, are called the genetically effective cells (GEC). The GECN was calculated using segregation ratios for deletions, according to the method of $\mathrm{Li}$ and Rédei [87] and Hodgdon et al. [46] with modifications as needed for the $\mathrm{RH}$ population (Table 3 ). In an $\mathrm{M}_{2}$ population, the progeny descended from a single (germ line) cell, is expected to show a simple Mendelian segregation ratio of 3:1 (AA, 2Aa, aa) for any recessive mutation at a given heterozygous locus $\left(\mathrm{Aa}\right.$ in $\mathrm{M}_{1}$ ). However in case of RHs, deletion-type mutations are expected, so the $\mathrm{RH}_{0}$ plant is in a hemizygous condition (A-) for a deleted locus. Moreover, in the case of $\mathrm{RHs}, \mathrm{RH}_{0}\left(\mathrm{Aa}\right.$; same as $\mathrm{M}_{1}$ ) plants are not selfed, but rather are crossed to a second line which is null (--) for the particular locus under study. Hence, $\mathrm{RH}_{1}$ plants originating from the same $\mathrm{RH}_{0}$ female plant (defined as $\mathrm{RH}_{1}$ family) segregate in a $1: 1$ (A-, -) ratio if the $\mathrm{GECN}=1$. When the germline, at the time of the irradiation, comprises of more than one cell (GECN $>1$ ), an alteration of the segregation ratio will be observed (Table 3) since not all cells are expected to have identical deletions (or mutations) at a given locus in the same meristem at the same time.

Deletion data of 35 SSR markers for $339 \mathrm{DGRH}_{1}$ plants belonging to $29 \mathrm{RH}_{1}$ families was used to calculate the segregation ratio for each unique deletion mutation. Deletion mutations for individual chromosomes were treated separately. Using the frequency of a particular marker deletion mutation in $\mathrm{RH}_{1}$ families, the GECN in a $\mathrm{RH}_{1}$ population can be calculated as follows:

$$
\mathrm{GECN}=\mathrm{t} / 2 \mathrm{~d}
$$

Where $t$ is total number of siblings in a specific $\mathrm{RH}_{1}$ family, and $d$ is the total number of siblings in a $\mathrm{RH}_{1}$ family with same deletion mutation.

\footnotetext{
Abbreviations

BAC: Bacterial artificial chromosome; cR: Centi-Rays; GECN: Genetically effective cell number; Gy: Gray; LDN: Langdon; IWGSC: International wheat genome sequencing consortium; RH: Radiation hybrid; RJM: Repeat DNA junction marker.
}

\section{Competing interests}

The authors declare that they have no competing interests.

\section{Authors' contributions}

AK and SFK designed research; AK, KS and MMdeJ performed the research; AK, KS, MJI, FB, FG and PMAK analyzed the data; TD, YW, MCL, YQG, GRL and JD provided markers; SSX provided seed material; OAIA and AMD developed iterative framework mapping script; AK drafted the manuscript with comments from all authors; MJI, FG and SFK managed the project. All authors read and approved the final manuscript.

\section{Acknowledgements}

The authors wish to thank Justin Hegstad and Allen Peckrul for assistance in the development of $\mathrm{RH}$ panel and capable technical support throughout the research. We would also like to thank Dr. Phillip E. McClean for reviewing the manuscript. Thanks are also due to the members of external scientific advisory board, Drs. Ronald Phillips, Etienne Paux, Rod Wing and Volker Brendel for all their suggestions and comments. This work was supported by funding from the National Science Foundation, Plant Genome Research Program (NSF-PGRP) grant No. IOS-0822100 to SFK.

\section{Author details}

${ }^{1}$ Department of Plant Sciences, North Dakota State University, Fargo, ND 58108, USA. ${ }^{2}$ Department of Computer Sciences, North Dakota State University, Fargo, ND 58105, USA. ${ }^{3}$ USDA-ARS, Western Regional Research Center, Albany, CA94710, USA. ${ }^{4}$ Department of Plant Sciences, University of California, Davis, CA 95616, USA. ${ }^{5}$ USDA-ARS, Northern Crop Science Laboratory, Fargo, ND 58102, USA. ${ }^{6}$ Present address: Math, Science and Technology Department, University of Minnesota, Crookston, MN 56716, USA.

Received: 30 August 2012 Accepted: 31 October 2012

Published: 5 November 2012

\section{References}

1. Arumuganathan K, Earle ED: Nuclear DNA content of some important plant species. Plant Mol Biol Rep 1991, 9:208-218.

2. Li W, Zhang P, Fellers JP, Friebe B, Gill BS: Sequence composition, organization, and evolution of the core Triticeae genome. Plant J 2004, 40:500-511.

3. Gill KS, Gill BS, Endo TR: Achromosome region-specific mapping strategy reveals gene-rich telometric ends in wheat. Chromosoma 1993, 102:374-381.

4. Lukaszewski A, Curtis CA: Physical distribution of recombination in B-genome chromosome of tetraploid wheat. Theor Appl Genet 1993, 86:121-127.

5. Erayman M, Sandhu D, Sidhu D, Dilbirligi M, Baenziger PS, Gill KS: Demarcating the gene-rich regions of the wheat genome. Nucleic Acids Res 2004, 32:3546-3565.

6. Mézard C: Meiotic recombination hotspots in plants. Biochem Soc Trans 2006, 34:part 4.

7. Saintenac C, Falque M, Martin OC, Paux E, Feuillet C, Sourdille P: Detailed recombination studies along chromosome $3 \mathrm{~B}$ provide new insights on crossover distribution in wheat (Triticum aestivum L.). Genetics 2009, 181:393-403.

8. Paux E, Sourdille P, Salse J, Saintenac C, Choulet F, Leroy P, Korol A, Michalak M, Kianian S, Spielmeyer W, Lagudah E, Somers D, Kilian A, Alaux M, Vautrin S, Bergès H, Eversole K, Appels R, Safar J, Simkova H, Dolezel J, Bernard M, Feuillet C: A physical map of the 1-gigabase bread wheat chromosome 3B. Science 2008, 322:101-104.

9. Faraut T, de Givry S, Hitte C, Lahbib-Mansais Y, Morisson M, Milan D, Schiex T, Servin B, Vignal A, Galibert F, Yerle M: Contribution of radiation hybrids to genome mapping in domestic animals. Cytogenet Genome Res 2009, 126:21-33.

10. Goss $\mathrm{S}$, Harris $\mathrm{H}$ : New method for mapping genes in human chromosomes. Nature 1975, 255:680-684.

11. Ghavami F, Michalak MK, Riera-Lizarazu O, Gu YQ, Thilmony R, Maan SS, Kianian SF: A new strategy to map scs genes: Combining radiation hybrid mapping with high resolution genetic mapping [abstract]. Plant and Animal Genome XVIII Conference: 9-13 January 2010, San Diego, California, USA 2010.

12. Xue S, Zhang Z, Lin F, Kong Z, Cao Y, Li C, Yi H, Mei M, Zhu H, Wu J, Xu H, Zhao D, Tian D, Zhang C, Ma Z: A high-density intervarietal map of the 
wheat genome enriched with markers derived from expressed sequence tags. Theor App/ Genet 2008, 117:181-189.

13. Yerle M, Pinton P, Delcros C, Arnal N, Milan D, Robic A: Generation and characterization of a 12,000-rad radiation hybrid panel for fine mapping in pig. Cytogenet Genome Res 2002, 97:219-228.

14. Hossain KG, Riera-Lizarazu O, Kalavacharla V, Vales MI, Maan SS, Kianian SF: Radiation hybrid mapping of the species cytoplasm-specific $\left(\mathrm{scs}^{\mathrm{ae}}\right)$ gene in wheat. Genetics 2004, 168:415-423.

15. Weikard R, Goldammer T, Laurent P, Womack JE, Kuehn C: A gene-based high-resolution comparative radiation hybrid map as a framework for genome sequence assembly of a bovine chromosome 6 region associated with QTL for growth, body composition, and milk performance traits. BMC Genomics 2006, 7:53.

16. Karere GM, Froenicke L, Millon L, Womack JE, Lyons LA: A high-resolution radiation hybrid map of rhesus macaque chromosome 5 identifies rearrangements in the genome assembly. Genomics 2008, 92:210-218.

17. Lewin HA, Larkin DM, Pontius J, O'Brien SJ: Every genome sequence needs a good map. Genome Res 2009, 19:1925-1928.

18. Riera-Lizarazu O, Vales Ml, Ananiev EV, Rines HW, Phillips RL: Production and characterisation of maize chromosome 9 radiation hybrids derived from an oat-maize addition line. Genetics 2000, 156:327-339.

19. Kynast RG, Okagaki RJ, Galatowitsch MW, Granath SR, Jacobs MS, Stec AO, Rines HW, Phillips RL: Dissecting the maize genome by using chromosome addition and radiation hybrid lines. Proc Natl Acad Sci USA 2004, 101:9921-9926.

20. Wardrop J, Snape J, Powell W, Machray G: Constructing plant radiation hybrid panels. Plant J 2002, 31:223-228.

21. Gao W, Chen ZJ, Yu JZ, Raska D, Kohel RJ, Womack JE, Stelly DM: Widecross whole-genome radiation hybrid mapping of cotton (gossypium hirsutum L.). Genetics 2004, 167:1317-1329.

22. Gao W, Chen ZJ, Yu JZ, Kohel RJ, Womack JE, Stelly DM: Wide-cross whole-genome radiation hybrid mapping of the cotton (Gossypium barbadense L.) genome. Mol Gen Genomics 2006, 275:105-113.

23. Kalavacharla VS, Hossain KG, Gu Y, Riera-Lizarazu O, Vales MI, Bhamidimarri S, Gonzalez-Hernandez JL, Maan SS, Kianian SF: High-resolution radiation hybrid map of wheat chromosome 1D. Genetics 2006, 173:1089-1099.

24. Riera-Lizarazu O, Leonard JM, Tiwari VK, Kianian SF: A method to produce radiation hybrids for the $\mathrm{D}$-genome chromosomes of wheat (triticum aestivum L.). Cytogenet Genome Res 2010, 129:234-240.

25. Kumar A, Bassi FM, Paux E, Al-Azzam O, de Jimenez MM, Denton AM, Gu YQ Huttner E, Kilian A, Kumar S, Goyal A, Iqbal MJ, Tiwari V, Dogramaci M, Balyan HS, Dhaliwal HS, Gupta PK, Randhawa GS, Feuillet C, Pawlowski WP, Kianian SF: DNA repair and crossing over favor similar chromosome regions as discovered in radiation hybrid of Triticum. BMC Genomics 2012, 13:339.

26. Kumar N, Kulwal PL, Balyan HS, Gupta PK: QTL mapping for yield and yield contributing traits in two mapping populations of bread wheat. Mol Breed 2007, 19:163-177.

27. Krattinger SG, Lagudah ES, Spielmeyer W, Singh RP, Huerta-Espino J, McFadden H, Bossolini E, Selter LL, Keller B: A putative ABC transporter confers durable resistance to multiple fungal pathogens in wheat. Science 2009, 323:1360-1363.

28. Landjeva S, Lohwasser U, Börner A: Genetic mapping within the wheat D genome reveals QTL for germination, seed vigour and longevity, and early seedling growth. Euphytica 2010, 171:129-143.

29. Jantasuriyarat C, Vales MI, Watson CJW, Riera-Lizarazu O: Identification and mapping of genetic loci affecting the free-threshing habit and spike compactness in wheat (Triticum aestivum L.). Theor Appl Genet 2004, 108:261-273.

30. Van Deynze AE, Dubcovsky J, Gill KS, Nelson JC, Sorrells ME, Dvorák J, Gill BS, Lagudah ES, McCouch SR, Appels R: Molecular-genetic maps for group 1 chromosomes of Triticeae species and their relation to chromosomes in rice and oat. Genome 1995, 38:45-59.

31. Börner A, Schumann E, Fürste A, Cöster H, Leithold B, Röder MS, Weber WE: Mapping of quantitative trait loci for agronomic important characters in hexaploid wheat (Triticum aestivum L.). Theor Appl Genet 2002, 105:921-936.

32. Kulwal PL, Roy JK, Balyan HS, Gupta PK: QTL mapping for growth and leaf characters in bread wheat. Plant Sci 2003, 164:267-277.

33. Kulwal PL, Singh R, Balyan HS, Gupta PK: Genetic basis of pre-harvest sprouting tolerance using single-locus and two-locus QTL analyses in bread wheat. Funct Integr Genom 2004, 4:94-101.
34. Kulwal PL, Kumar N, Kumar A, Gupta RK, Balyan HS, Gupta PK: Gene networks in hexaploid wheat: interacting quantitative trait loci for grain protein content. Funct Integr Genome 2005, 5:254-259

35. Dubcovsky J, Dvorak J: Genome plasticity a key factor in the success of polyploid wheat under domestication. Science 2007, 316:1862-1866.

36. Dvorak J, Luo M, Yang Z, Zhang H: Genetic evidence on the origin of T. aestivum L. In The origins of agriculture and crop domestication. Edited by Damania A, Valkoun J, Willcox G, Qualset C. Aleppo, Syria: ICARDA 1998:235-251

37. Xu Z, Deal KR, Li W, Covaleda L, Chang Y-L, Dvorak J, Luo MC, Gill BS, Anderson OD, Zhang HB: Construction and characterization of five large-insert BAC and BIBAC libraries of Aegilops tauschii, the diploid donor of the wheat $D$ genome [abstract]. Plant and Animal Genome $X$ Conference:12-16 January 2002 San Diego, California, USA 2002, 101

38. Luo MC, Deal KR, Akhunov ED, Akhunova AR, Anderson OD, Anderson JA, Blake N, Clegg MT, Coleman-Derr D, Conley EJ, Crossman CC, Dubcovsky J, Gill BS, Gu YQ, Hadam J, Heo HY, Huo N, Lazo G, Ma Y, Matthews DE, McGuire PE, Morrell PL, Qualset CO, Renfro J, Tabanao D, Talbert LE, Tian C, Toleno DM, Warburton ML, You FM, Zhang W, Dvorak J: Genome comparisons reveal a dominant mechanism of chromosome number reduction in grasses and accelerated genome evolution in Triticeae. PNAS USA 2009, 106:15780-15785.

39. You FM, Huo N, Deal KR, Gu YQ, Luo MC, McGuire PE, Dvorak J, Anderson OD: Annotation-based genome-wide SNP discovery in the large and complex Aegilops tauschii genome using next-generation sequencing without a reference genome sequence. BMC Genomics 2011, 12:59.

40. Friesen TL, Xu SS, Harris MO: Stem rust, tan spot, Stagonospora nodorum blotch, and hessian fly resistance in langdon durum-Aegilops tauschii synthetic hexaploid wheat lines. Crop Sci 2008, 48:1062-1070.

41. Somers DJ, Isaac P, Edwards K: A high-density microsatellite consensus map for bread wheat (Triticum aestivum L.). Theor Appl Genet 2004, 109:1105-1114.

42. Sourdille P, Singh S, Cadalen T, Brown-Guedira GL, Gay G, Qi L, Gill BS, Dufour $P$, Murigneux A, Bernard M: Microsatellite-based deletion bin system for the establishment of genetic-physical map relationships in wheat (Triticum aestivum L.). Funct Integr Genomics 2004, 4:12-25.

43. Conley EJ, Nduati V, Gonzalez-Hernandez JL, Mesfin A, Trudeau-Spanjers M, Chao S, Lazo GR, Hummel DD, Anderson OD, Qi LL, Gill BS, Echalier B, Linkiewicz AM, Dubcovsky J, Akhunov ED, Dvorák J, Peng JH, Lapitan NL, Pathan MS, Nguyen HT, Ma XF, Miftahudin, Gustafson JP, Greene RA, Sorrells ME, Hossain KG, Kalavacharla V, Kianian SF, Sidhu D, Dilbirligi M, et al: A 2600-locus chromosome bin map of wheat homoeologous group 2 reveals interstitial gene-rich islands and colinearity with rice. Genetics 2004, 168(2):625-637.

44. Wanjugi H, Coleman-Derr D, Huo N, Kianian SF, Luo MC, Wu J, Anderson O, Gu YQ: Rapid development of PCR-based genome-specific repetitive DNA junction markers in wheat. Genome 2009, 52:576-587.

45. Dolezel J, Simkova H, Kubalakova M, Safar J, Suchankova P, Cihalikova J, Bartos J, Valarik M: Chromosome genomics in the Triticeae. In Genetics and genomics of the triticeae. Edited by Feuillet C, Muehlbauer GJ. Berlin: Springer; 2009:285-316

46. Hodgdon AL, Marcus AH, Arenas P, Rosichan JL, Bogyo TP, Nilan RA: Ontogeny of the barley plant as related to mutation expression and detection of pollen mutations. Environ Health Perspect 1981, 37:5

47. Johri MM, Coe EH: Clonal analysis of corn plant development I. The development of the tassel and ear shoot. Dev Biol 1983, 97:154-172.

48. Hitte C, Madeoy J, Kirkness EF, Priat C, Lorentzen TD, Senger F, Thomas D, Derrien T, Ramirez C, Scott C, Evanno G, Pullar B, Cadieu E, Oza V, Lourgant K, Jaffe DB, Tacher S, Dréano S, Berkova N, André C, Deloukas P, Fraser C, Lindblad-Toh K, Ostrander EA, Galibert F: Facilitating genome navigation: survey sequencing and dense radiation-hybrid gene mapping. Nat Rev Genet 2005, 6:643-648.

49. Endo TR, Gill BS: The deletion stocks of common wheat. J Hered 1996, 87:295-307.

50. Olivier M, Aggarwal A, Allen J, Almendras AA, Bajorek ES, Beasley EM, Brady SD, Bushard JM, Bustos VI, Chu A, Chung TR, De Witte A, Denys ME, Dominguez R, Fang NY, Foster BD, Freudenberg RW, Hadley D, Hamilton LR, Jeffrey TJ, Kelly L, Lazzeroni L, Levy MR, Lewis SC, Liu X, Lopez FJ, Louie B, Marquis JP, Martinez RA, Matsuura MK, et al: A high-resolution radiation 
hybrid map of the human genome draft sequence. Science 2001, 291:1298-1302.

51. Watkins AE: Hybrid sterility and incompatibility. J Genet 1932, 25:125-162.

52. Thompson WP, Cameron DR: Chromosome numbers in functioning germ-cells of species hybrids in wheat. Genetics 1928, 13:456-469.

53. Haig $D$, Westoby M: Genomic imprinting in endosperm: its effect on seed development in crosses between species, and between different ploidies of the same species, and its implications for the evolution of apomixis. Phil Trans R Soc Lond 1991, 333:1-13.

54. Thompson WP: Causes of difference in success of reciprocal interspecific crosses. Am Nat 1930, 64:407-421.

55. Thompson WP: Shriveled endosperm in species crosses in wheat, its cytological causes and genetical effects. Genetics 1930, 15:99-113.

56. Raissig MT, Baroux C, Grossniklaus U: Regulation and flexibility of genomic imprinting during seed development. Plant Cell 2011, 23:16-26.

57. Autran D, Baroux C, Raissig MT, Lenormand T, Wittig M, Grob S, Steimer A Barann M, Klostermeier UC, Leblanc O, Vielle-Calzada JP, Rosenstiel P Grimanelli D: Maternal epigenetic pathways control parental contributions to Arabidopsis early embryogenesis. Cell 2011, 145:707-719.

58. Redei GP, Koncz C: Classical mutagenesis. In Methods in Arabidopsis research Edited by Koncz C, Chua NH, Schell J. Singapore: World Scientific; 1992:16-82.

59. Blonstein AD, Parry AD, Horgan R, King PJ: Acytokinin-resistant mutant of Nicotiana plumbaginifolia is wilty. Planta 1991, 183:244-250.

60. Blonstein AD, Stirnberg P, King PJ: Mutants of Nicotiana plumbaginifolia with specific resistance to auxin. Mol Gen Genet 1991, 228:361-371.

61. Pelsy F, Kronenberger J, Pollien JM, Caboche $\mathrm{M}: \mathrm{M}_{2}$ seed screening for nitrate reductase deficiency in Nicotiana plumbaginifolia. Plant Sci 1991, 76:109-114

62. Carroll BJ, Gresshoff PM, Delves AC: Inheritance of supernodulation in soybean and estimation of the genetically effective cell number. Theor Appl Genet 1988, 76:54-58.

63. Bertagne-Sagnard B, Fouilloux G, Chupeau Y: Induced albino mutations as a tool for genetic analysis and cell biology in flax (Linum usitatssimum). J Exp Bot 1996, 47:189-194.

64. Anderson EG, Longley $A E, L i C H$, Retherford KL: Hereditary effects produced in maize by radiations from the Bikini atomic bomb. 1. Studies on seedlings and pollen of the exposed generation. Genetics 1949, 34:639-646.

65. Jones HB: Hybrid selection as a method of increasing mapping power for radiation hybrids. Genome Res 1996, 6:761-769.

66. La Rota M, Kantety RV, Yu JK, Sorrells ME: Nonrandom distribution and frequencies of genomic and EST-derived microsatellite markers in rice, wheat, and barley. BMC Genomics 2005, 6:23.

67. Paux E, Roger D, Badaeva E, Gay G, Bernard M, Sourdille P, Feuillet C: Characterizing the composition and evolution ofhomoeologous genomes in hexaploid wheat through BAC-end sequencing on chromosome 3B. Plant J 2006, 48:463-474.

68. Liu S, Yeh C-T, Ji T, Ying K, Wu H, Tang HM, Fu Y, Nettleton D, Schnable PS: Mu transposon insertion sites and meiotic recombination events colocalize with epigenetic marks for open chromatin across the maize genome. PLoS Genet 2009, 5:e1000733.

69. Varshney RK, Balyan HS, Langridge P: Wheat. In Genome mapping \& molecular breeding in plants viol. 1: cereals \& millets. Hiedelberg, Germany: Springer-Verlag GMBH; 2006:79-134

70. Feuillet C, Leach JE, Rogers J, Schnable PS, Eversole K: Crop genome sequencing: lessons and rationales. Trends Plant Sci 2011, 16:77-88.

71. Stewart EA, McKusick KB, Aggarwal A, Bajorek E, Brady S, Chu A, Fang N, Hadley D, Harris M, Hussain S, Lee R, Maratukulam A, O'Connor K, Perkins S, Piercy M, Qin F, Reif T, Sanders C, She X, Sun WL, Tabar P, Voyticky S, Cowles S, Fan JB, Mader C, Quackenbush J, Myers RM, Cox DR: An STS-based radiation hybrid map of the human genome. Genome Res 1997, 7:422-433.

72. Lander ES, Linton LM, Birren B, Nusbaum C, Zody MC, Baldwin J, Devon K, Dewar K, Doyle M, FitzHugh W, Funke R, Gage D, Harris K, Heaford A, Howland J, Kann L, Lehoczky J, LeVine R, McEwan P, McKernan K, Meldrim J, Mesirov JP, Miranda C, Morris W, Naylor J, Raymond C, Rosetti M, Santos R, Sheridan A, Sougnez C, et al: Initial sequencing and analysis of the human genome. Nature 2001, 409:860-921.

73. Waterston RH, Lindblad-Toh K, Birney E, Rogers J, Abril JF, Agarwal P, Agarwala $\mathrm{R}$, Ainscough $\mathrm{R}$, Alexandersson $\mathrm{M}$, An $\mathrm{P}$, Antonarakis $\mathrm{SE}$, Attwood J, Baertsch R, Bailey J, Barlow K, Beck S, Berry E, Birren B, Bloom T, Bork P, Botcherby M, Bray N, Brent MR, Brown DG, Brown SD, Bult C, Burton J, Butler J, Campbell RD, Carninci P, et al: Initial sequencing and comparative analysis of the mouse genome. Nature 2002, 420:520-562.

74. Gibbs RA, Weinstock GM, Metzker ML, Muzny DM, Sodergren EJ, Scherer S, Scott G, Steffen D, Worley KC, Burch PE, Okwuonu G, Hines S, Lewis L, DeRamo C, Delgado O, Dugan-Rocha S, Miner G, Morgan M, Hawes A, Gill R, Celera, Holt RA, Adams MD, Amanatides PG, Baden-Tillson H, Barnstead M, Chin S, Evans CA, Ferriera S, Fosler C, et al: Genome sequence of the Brown Norway rat yields insights into mammalian evolution. Nature 2004, 428:493-521.

75. Lindblad-Toh K, Wade CM, Mikkelsen TS, Karlsson EK, Jaffe DB, Kamal M, Clamp M, Chang JL, Kulbokas EJ 3rd, Zody MC, Mauceli E, Xie X, Breen M, Wayne RK, Ostrander EA, Ponting CP, Galibert F, Smith DR, DeJong PJ, Kirkness E, Alvarez P, Biagi T, Brockman W, Butler J, Chin CW, Cook A, Cuff J, Daly MJ, DeCaprio D, Gnerre S, et al: Genome sequence, comparative analysis and haplotype structure of the domestic dog. Nature 2005, 438:803-819.

76. Elsik CG, Tellam RL, Worley KC, Gibbs RA, Muzny DM, Weinstock GM, Adelson DL, Eichler EE, Elnitski L, Guigó R, Hamernik DL, Kappes SM, Lewin HA, Lynn DJ, Nicholas FW, Reymond A, Rijnkels M, Skow LC, Zdobnov EM, Schook L, Womack J, Alioto T, Antonarakis SE, Astashyn A, Chapple CE, Chen HC, Chrast J, Câmara F, Ermolaeva O, Henrichsen CN, et al: The genome sequence of taurine cattle: a window to ruminant biology and evolution. Science 2009, 324:522-528.

77. Wade CM, Giulotto E, Sigurdsson S, Zoli M, Gnerre S, Imsland F, Lear TL, Adelson DL, Bailey E, Bellone RR, Blöcker H, Distl O, Edgar RC, Garber M, Leeb T, Mauceli E, MacLeod JN, Penedo MC, Raison JM, Sharpe T, Vogel J, Andersson L, Antczak DF, Biagi T, Binns MM, Chowdhary BP, Coleman SJ, Della Valle G, Fryc S, Guérin G, et al: Genome sequence, comparative analysis, and population genetics of the domestic horse. Science 2009, 326:865-867.

78. Sutka J, Galiba G, Vagujfalvi A, Gill BS, Snape JW: Physical mapping of Vrn-A1 and Fr1 genes on chromosome 5A of wheat using deletion line. Theor Appl Genet 1999, 99:199-202.

79. Raman H, Zhang K, Cakir M, Appels R, Garvin DF, Maron LG, Kochian LV, Moroni JS, Raman R, Imtiaz M, Drake-Brockman F, Waters I, Martin P, Sasaki T, Yamamoto Y, Matsumoto H, Hebb DM, Delhaize E, Ryan PR, et al: Molecular characterization and mapping of ALMT1, the aluminiumtolerance gene of bread wheat (Triticum aestivum L.). Genome 2005, 8:781-791.

80. Al-Kaff N, Knight E, Bertin I, Foote T, Hart N, Griffiths S, Moore G: Detailed dissection of the chromosomal region containing the Ph1 locus in wheat Triticum aestivum: with deletion mutants and expression profiling. Ann Bot 2008, 101:863-872.

81. Eberhard F, Zhang P, Lehmensiek A, Hare R, Simpfendorfer S, Sutherland MW: Chromosome composition of an $\mathrm{F}_{2}$ Triticum aestivum $\times$ Tturgidum spp. durum cross analysed by DArT markers and MCFISH. Crop Pasture Sci 2010, 61:619-624.

82. Martin A, Simpfendorfer S, Hare RA, Eberhard FS, Sutherland MW: Retention of D genome chromosomes in pentaploid wheat crosses. Heredity 2011, 107:315-319.

83. You FM, Wanjugi H, Huo N, Lazo GL, Luo MC, Anderson OD, Dvorak J, Gu YQ: RJPrimers: unique transposable element insertion junction discovery and PCR primer design for marker development. Nucleic Acids Res 2010, 38:W313-W320

84. Guidet F, Rogowsky P, Taylor C, Song W, Langridge P: Cloning and characterisation of a new rye-specific repeated sequence. Genome 1991, 34:81-87.

85. de Givry S, Bouchez M, Chabrier P, Milan D, Schiex T: CARTHAGENE: multipopulation integrated genetic and radiated hybrid mapping. Bioinformatics 2005, 21:1703-1704.

86. Al-Azzam O, Al-Nimer L, Chitraranjan C, Denton AM, Kumar A, Bassi F, Iqbal MJ, Kianian SF: Network-based Filtering of Unreliable Markers in Genome Mapping. In proceedings of the 11th International Conference on Machine Learning and Applications (ICMLA): 18-21 Dec. 2011 Honolulu, HI 2011.

87. Li SL, Redei GP: Estimation of mutation rate in autogamous diploids. Radiat Bot 1969, 9:125.

doi:10.1186/1471-2164-13-597

Cite this article as: Kumar et al: Physical mapping resources for large plant genomes: radiation hybrids for wheat D-genome progenitor Aegilops tauschii. BMC Genomics 2012 13:597. 